\title{
Emergence of Contrast of Cognitive-Valuing Features of Mathematics Across Global Classrooms
}

\author{
Joshua Edson Gorme Ordiz \\ Southern Leyte State University, Philippines \\ e-mail: joshuaedsonordiz@slsuonline.edu.ph
}

\begin{abstract}
Processes and patterns in mathematics education are shaped into dynamic complex systems referred to as a new structure because of the close interplay and networks of different social atoms. The study attempts to understand the interactions at the macro level using exploratory data analysis of secondary data from an international assessment organization in order to discover and fathom the interrelationship of the characteristics namely achievement in mathematics and valuing attitude towards math. Findings showed that global classroom displayed a decline of performance as the valuing to the discipline intensifies. Further analysis found out that presently, the nature of valuing is extrinsic which focuses in the practical use of the subject. With this, behavior in learning mathematics is not positive when geared towards usefulness; but it will dramatically change the achievement when approach is modified to being a desirable disciple.
\end{abstract}

Keywords: beauty of math, value of mathematics, performance in math, complex adaptive system, self-organization

How to Cite: Ordiz, J.E.G (2020). Emergence of Contrast of Cognitive-Valuing Features of Mathematics Across Global Classrooms. International Journal on Emerging Mathematics Education, 4(1), 11-22. http://dx.doi.org/10.12928/ijeme.v3i2.15820

\section{INTRODUCTION}

Human behavior is complex and susceptible in the dynamic social environment occupied with distinct individual. These different emotions, attitudes, and experiences of the students influence a lot in the teaching-learning process, eventually in the attainment of the concept and application of Mathematics (Burton,2012; Beilock \& Willingham, 2014). Investigating a twenty-first-century mathematics classroom as to the teaching-learning process is best attributed when the locus of learning is shifted from individual thinking to collective social thinking because complexity in the performance of the subject will not show how other people influence the performance of the other (Newell, 2008). According to Davis and Sumara (2014), the students through their contact and interaction within and outside the teaching space will enabled them to self-organize into complex adaptive system.

Mathematics was never been a fond area in education despite the opportunities it offers to produce a comprehensive learner. The subject sort features into becoming an orderly and systematic individual, but these potential chances were either enriched by few or eradicated by many through complex social activities. The study explores the achievement in mathematics and valuing attitude towards the discipline; it will showcase how these areas of human activity respond to each other as a social atom at a broader scope - the collective approach of the new structure. Ma and Xu (2004) explained that achievement and valuing exemplifies a reciprocated causal relationship present to the majority of students taking the subject causing to a vulnerable connection. These chains of networks within oneself is out in the systems of complexes 
of another person which the study positioned to regard and discover the promising actions of a complex individual embodied with mental and emotional features.

According to Lansing (2003), complex global patterns demonstrate properties of self-organizing structures which are significant components to understand the novel properties arise in the interaction. However, these systems exhibited in social and environmental observations revealed non-linear dynamics focusing on deterministic chaos which make it difficult to predict emergent behavior (Folke; 2006, Lansing; 2003). Added by Levin (2003), evolution of the agents were powerful at the macro level, therefore understanding the development of the emergent structure requires deep focused in learning the chemistry of their complexes and how these networks affect other systems forming individual synergy. Building of connections and interactions promote increase of information flow and create adaptation in an organization which is helpful throughout the system (Holden, 2005).

This study determined the emergent structure of the social atoms upon interaction with each other during the breakout point where every atom have adapted the existing patterns within oneself. This breakpoint formed the emergent behavior of one person when he/she deals with their performance in mathematics with due consideration on the valuing part of the discipline.

\section{Framework of the Study}

The study is anchored in the Complex Adaptive Systems where the complexities of the interactions of the agents (students as represented by countries) were accounted to reveal the emergent organization and understand the causal mechanism upon the building of connections (Fuller \& Moran, 2001). As such, mathematics classroom is composed of empirical features making it a huge and compressed network of individuals, these features may be in the form of mental and social structures. In the study, students valuing of the discipline and their achievement were confined to understand the emergent feature of the agents during the process of connectivity.

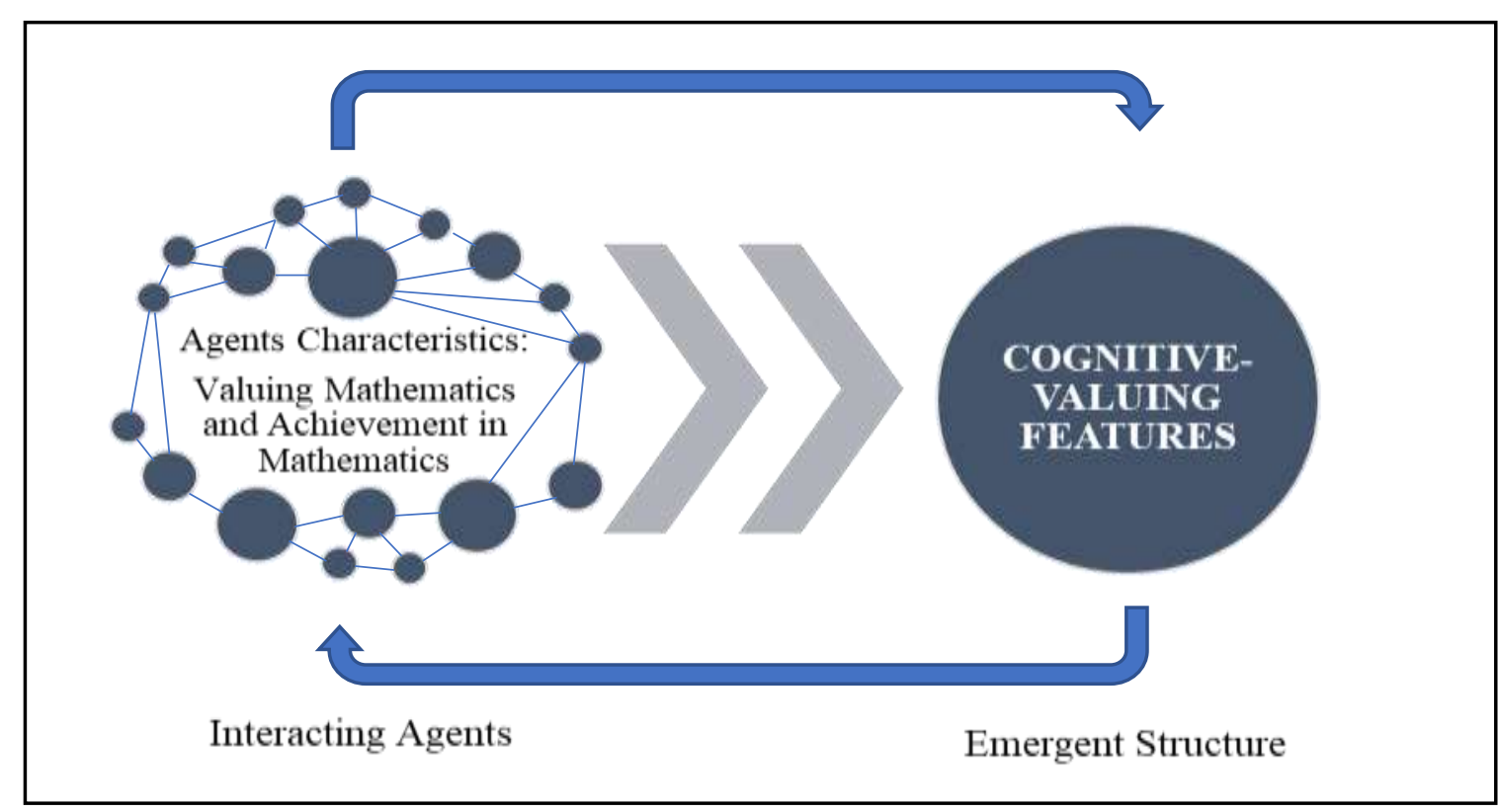

Figure 1. The framework of the emerging structure of the interacting agents' characteristics in a complex adaptive system

IJEME, Vol. 4, No. 1, March 2020, 11-22. 


\section{RESEARCH METHOD}

This study utilized exploratory data analysis in order to determine the emergent structure of the agents of the study. Data from Trends in International Mathematics and Science Study (TIMSS) covering the year 2015 were used to analyze and interpret the complex behavior of the globally participating countries. Data used in the 2015 International Results were the average scale gained by the countries in valuing mathematics and their mathematics achievement. These data represent the agent's characteristics which are primary component in understanding the new structure created in the interplay of the network of networks.

Table 1. Participating countries in Trends in International Mathematics and Science Study 2015 according to Score in Valuing Mathematics and Mathematics Achievement

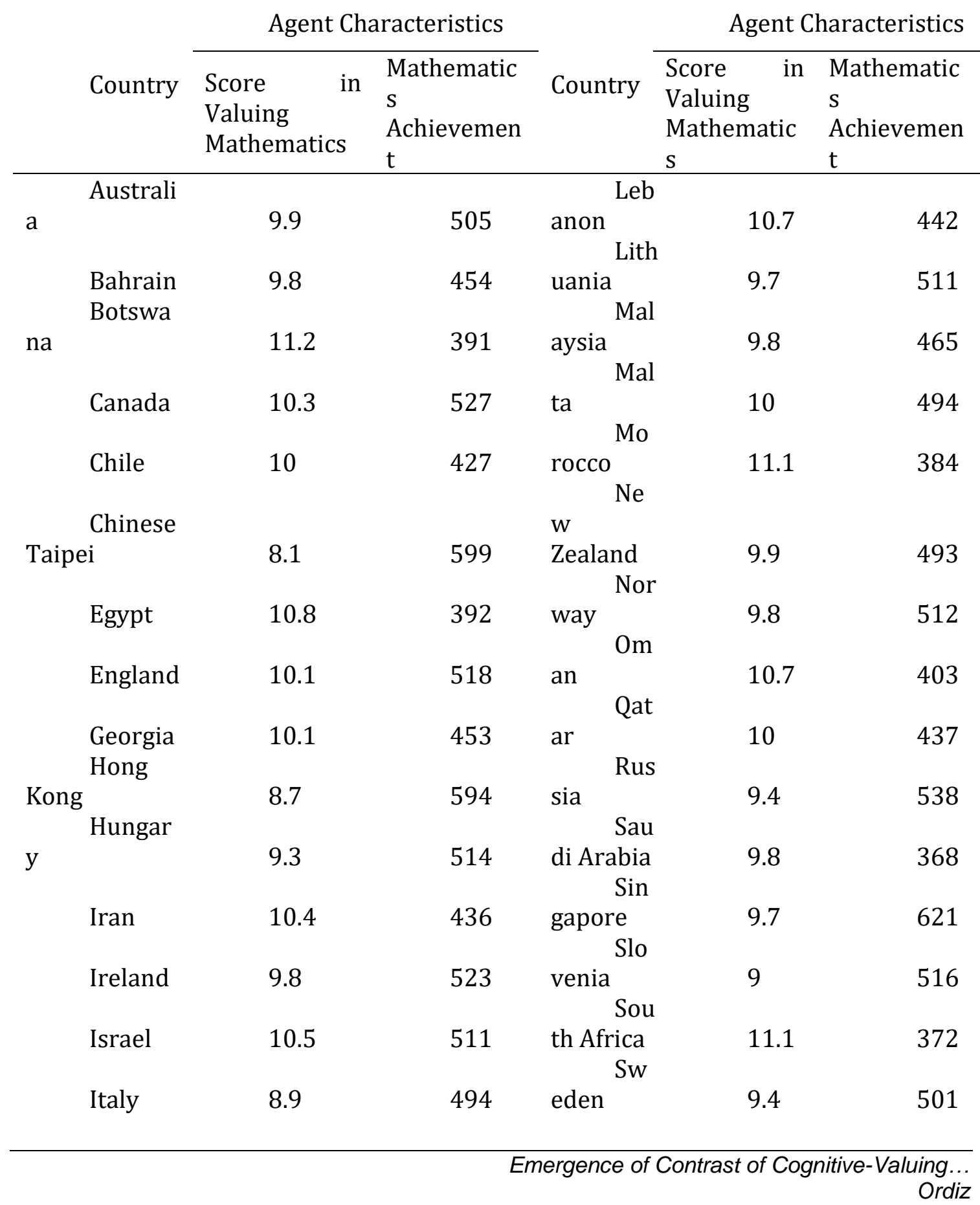




\begin{tabular}{|c|c|c|c|c|c|c|}
\hline & & & & Tha & & \\
\hline & Japan & 8.5 & 586 & iland & 10.3 & 431 \\
\hline & Jordan & 11 & 386 & key & 10.1 & 458 \\
\hline & Kazakh & & & UA & & \\
\hline stan & & 10 & 528 & $\mathrm{E}$ & 10 & 465 \\
\hline & & & & Uni & & \\
\hline & Korea & 8.6 & 606 & ted States & 10 & 518 \\
\hline & Kuwait & 10 & 392 & & & \\
\hline
\end{tabular}

The country is a social atom interacting to other countries through active networks building an emergent structure along the interaction. Scores in both valuing mathematics and achievement in math were restructured into percentage values to standardize the values in each of the countries. These values were treated using cluster analysis to determine the countries that are closely related in terms of their characteristics. The same data were subjected to factor analysis to define the new structure formed which becomes the feature score of the emergent structure of the study as shown in table 3.

Features of the agents both the emergent structure and sub-features were defined in table 2 to provide direction as to the characterization of the variables of the study.

Table 2. The Emergent Feature and Sub-Feature of the Agents and its definition in the study.

\begin{tabular}{ll}
\hline \multicolumn{1}{c}{ Features } & \multicolumn{1}{c}{ Definition } \\
\hline $\begin{array}{l}\text { Sub Feature } \\
\text { Valuing Mathematics }\end{array}$ & $\begin{array}{l}\text { Degree of agreement with on the Students Value } \\
\text { Mathematics (TIMSS, 2015). } \\
\text { Achievement in Math } \\
\text { Basic mathematical knowledge on solving problems } \\
\text { involving negative numbers, decimals, percentages, and } \\
\text { proportions, linear expressions and two- and three- } \\
\text { dimensional shape, read and interpret data in graphs and } \\
\text { tables, and basic knowledge of chance (TIMSS, 2015). }\end{array}$ \\
\hline $\begin{array}{l}\text { Emergent Feature } \\
\text { Cognitive-Valuing Feature }\end{array}$ & $\begin{array}{l}\text { Cognitive refers to the achievement while affective is the } \\
\text { valuing of mathematics. Feature may be Math Valuing (Low } \\
\text { Achievement, High Valuing), Math Performing (High } \\
\text { Achievement, Low Valuing), and Equal Weighing (Average } \\
\text { Achievement and Valuing) }\end{array}$ \\
\hline
\end{tabular}

IJEME, Vol. 4, No. 1, March 2020, 11-22. 
Table 3. Operation Loadings of the characteristics of the agents of the study in different conditions with feature score and its description.

\begin{tabular}{|c|c|c|c|}
\hline $\begin{array}{l}\text { Emergent } \\
\text { Structure }\end{array}$ & Operation & Feature Score & Description \\
\hline Math Valuing & Negative & \multirow{3}{*}{$\mathrm{F}=0.532$ Achievement -0.532 Attitude } & $\begin{array}{l}\text { Low } \\
\text { Achievement, } \\
\text { High Valuing }\end{array}$ \\
\hline Math Performing & Positive & & $\begin{array}{l}\text { High } \\
\text { Achievement, } \\
\text { Low Valuing }\end{array}$ \\
\hline Equal Weighing & $\begin{array}{l}\text { Zero/ } \\
\text { Close } \\
\text { Zero } \\
\end{array}$ & & $\begin{array}{l}\text { Equal } \\
\text { Achievement } \\
\text { and Valuing }\end{array}$ \\
\hline
\end{tabular}

Using the synergy calculator by Orano (2019), it calculated the number of connections of every country from other countries. Connections of a country do not matter as to what emergent structure they were classified.

\section{RESULTS AND DISCUSSION}

Understanding the development of complex adaptive systems involves understanding how support, associations and complexes of interaction emerge (Levin, 2003). Generation of the feature score and its number of connections generally established the indicator as to which countries group together forming the new structure.

Table 4. Summary of the Feature Score and Number of Connections of the Social Agents

\begin{tabular}{|c|c|c|c|c|c|}
\hline Country & $\begin{array}{l}\text { Feature } \\
\text { Score }\end{array}$ & $\begin{array}{l}\text { Number of } \\
\text { Connections }\end{array}$ & Country & $\begin{array}{l}\text { Feature } \\
\text { Score }\end{array}$ & $\begin{array}{l}\text { Number of } \\
\text { Connections }\end{array}$ \\
\hline Australia & 0.005 & 23 & Lebanon & 0.049 & 28 \\
\hline Bahrain & -0.019 & 9 & Lithuania & 0.014 & 18 \\
\hline Botswana & -0.090 & 31 & Malaysia & -0.013 & 10 \\
\hline Canada & 0.006 & 33 & Malta & -0.003 & 23 \\
\hline Chile & -0.039 & 9 & $\begin{array}{l}\text { Morocco } \\
\text { New }\end{array}$ & -0.091 & 28 \\
\hline Chinese Taipei & 0.103 & 0 & Zealand & -0.001 & 18 \\
\hline Egypt & -0.079 & 23 & Norway & 0.012 & 20 \\
\hline England & 0.007 & 28 & Oman & -0.070 & 23 \\
\hline Georgia & -0.028 & 17 & Qatar & -0.034 & 10 \\
\hline Hong Kong & 0.085 & 3 & $\begin{array}{l}\text { Russia } \\
\text { Saudi }\end{array}$ & 0.036 & 11 \\
\hline Hungary & 0.026 & 4 & Arabia & -0.065 & 0 \\
\hline Iran & -0.045 & 23 & Singapore & 0.072 & 34 \\
\hline Ireland & 0.018 & 23 & Slovenia & 0.035 & 1 \\
\hline Israel & -0.007 & 33 & South Africa & -0.097 & 28 \\
\hline Italy & 0.026 & 0 & Sweden & 0.016 & 4 \\
\hline Japan & 0.086 & 1 & Thailand & -0.045 & 17 \\
\hline
\end{tabular}




\begin{tabular}{llllll} 
Jordan & -0.087 & 28 & Turkey & -0.025 & 18 \\
Kazakhstan & 0.015 & 26 & $\begin{array}{l}\text { UAE } \\
\text { United }\end{array}$ & -0.019 & 17 \\
Korea & & & & \\
Kuwait & 0.094 & 3 & States & 0.010 & 24 \\
\hline
\end{tabular}

In the 39 participating countries of the international assessment in mathematics and science, Singapore, Canada, and Israel were the countries with the greatest number of connections to other countries with 34, 33 and 33 connections respectively. Meanwhile, countries Chinese Taipei, Italy and Saudi Arabia do not have any connections to any of the participating countries. In addition, Japan and Slovenia only have one connection out of 39 possible countries.

\begin{tabular}{l}
\hline Math Valuing (N=17) \\
\hline Iran (12), Lebanon (21), \\
Botswana (3), Egypt (7), Jordan (17), \\
Morocco (25), Oman (28), South \\
Africa (34) Singapore (32) Australia \\
(1), Malta (24), England (8), United \\
States (39), Israel (14), Canada (4), \\
Kazakhstan (18), and Ireland (13) \\
\hline Math Performing (N=10) \\
Chinese Taipei (6), Hong Kong \\
SAR (10), Korea (19), Saudi Arabia \\
(31), Japan (16), Kuwait (20), \\
Sweden (35), Italy (15), Hungary \\
(11), and Slovenia (33) \\
Equal Weighing (N=12) \\
New Zealand (26), Lithuania \\
Norway (27), Russian \\
Federation (30) Bahrain (2), Georgia \\
T), Turkey (37), Malaysia (23), \\
United Arab Emirates (38), Chile (5), \\
Thailand (36), and Qatar (29)
\end{tabular}

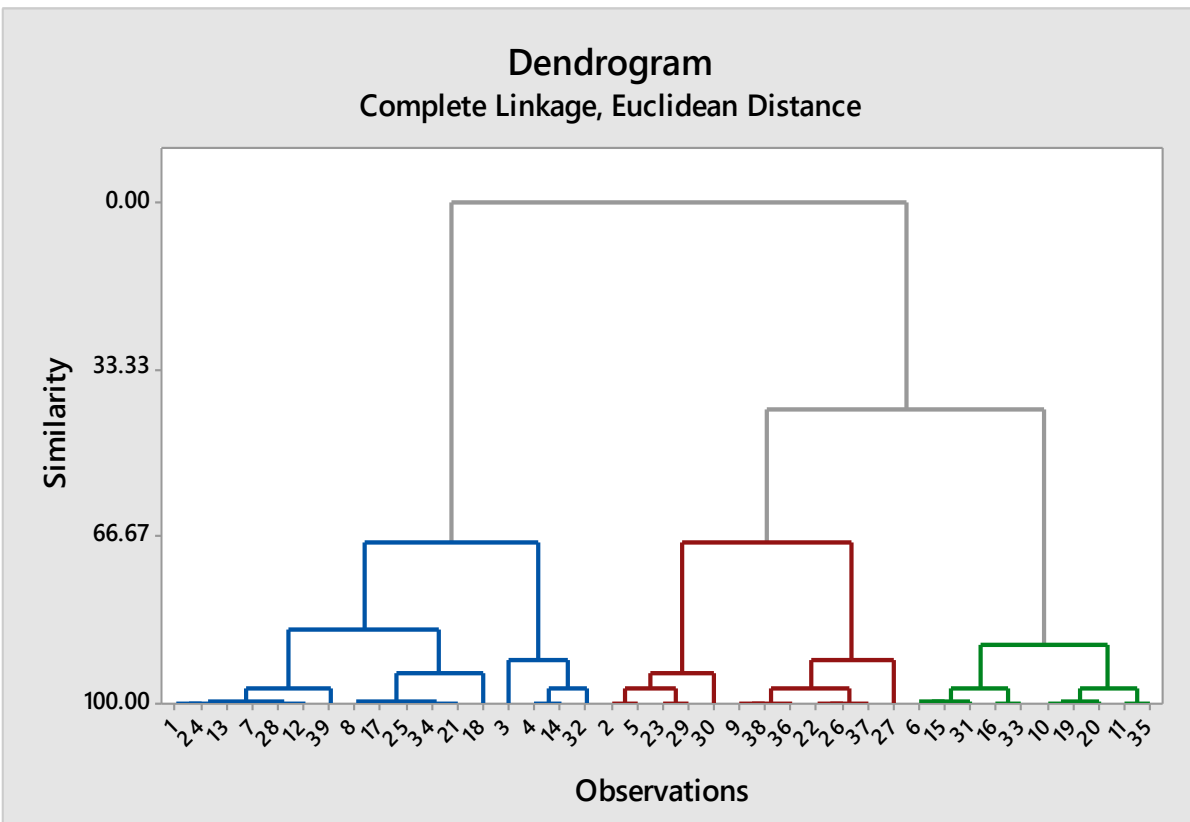

Figure 2. The Dendogram of the New Structure according to its Similarities and Countries part of the Cluster 


\section{Math Valuing Global Classroom}

In the study of Cavanagh (2008), it argues the need for reconsideration of intervention to ensure readiness of an individual in the discipline so that achievement in the later part of the course will be outstanding. This inclination is crucial in the success of any tasks in everyday life application of all the concepts of mathematics and even a contribution to the nation's economy (Reyna \& Brainerd, 2007). These actions imply the need to include math courses to ensure that competencies are covered.

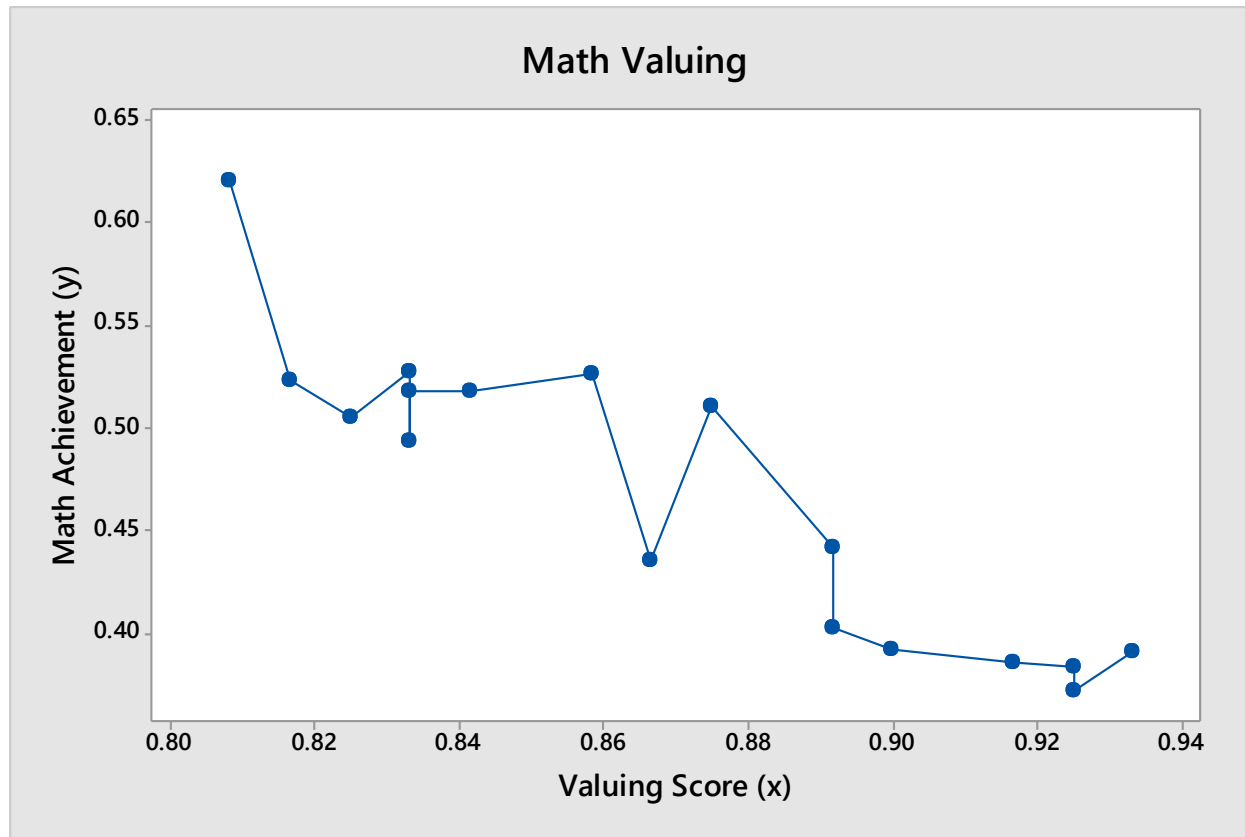

Figure 3. Scatter plot of the Math Valuing Countries in terms of Math Achievement and Valuing Score

In figure 4, valuing countries tend to have higher valuing to the subject, however, performs average to low in the achievement of mathematics. The scatter plot showed a downhill pattern of the performance as the valuing increases. Positive attitude towards the discipline provides an avenue for the academic community to integrate teaching strategies promoting courses in mathematics learning at best; however, this scheme lessens the appreciation to the discipline (Anderman, et.al, 2001). During the process of interaction of the students, educators have inculcated to the minds of the learners the importance of mathematics thereby shaping the need to value the importance but have no emphasis in the mastery of the content. Educators in the math valuing countries consider mathematics an important course because the subject is useful in the real-life application. There are ideas and concepts in the discipline that is necessary to survive in the competitive world.

Iran, Lebanon, Botswana, Egypt, Jordan, Morocco, Oman, South Africa, Singapore, Australia, Malta, England, United States, Israel, Canada, Kazakhstan, and Ireland were the countries grouped into one which value mathematics as a necessary subject useful in future use.

\section{Math Performing Global Classroom}

Countries part of the cluster exhibited a system that equipped their classroom to outperform the global classrooms. Explicitly, people are anxious to the impression of mathematics in general because of the difficulty of the subject which compromises the performance (Ashcraft and Krause, 2007). In fact, it is visible at high school and 
college level when students are avoiding coursework related to the discipline where only a percentage of students in a classroom significantly perform in class. Statistics showed that attitude and achievement in mathematics is negatively correlated which implies contrasting features (Karimi \& Venkatesan, 2009). For this cluster, importance of the subject is still considered but the curriculum focuses a global competition; by this student are working hand in hand to do well in the discipline.

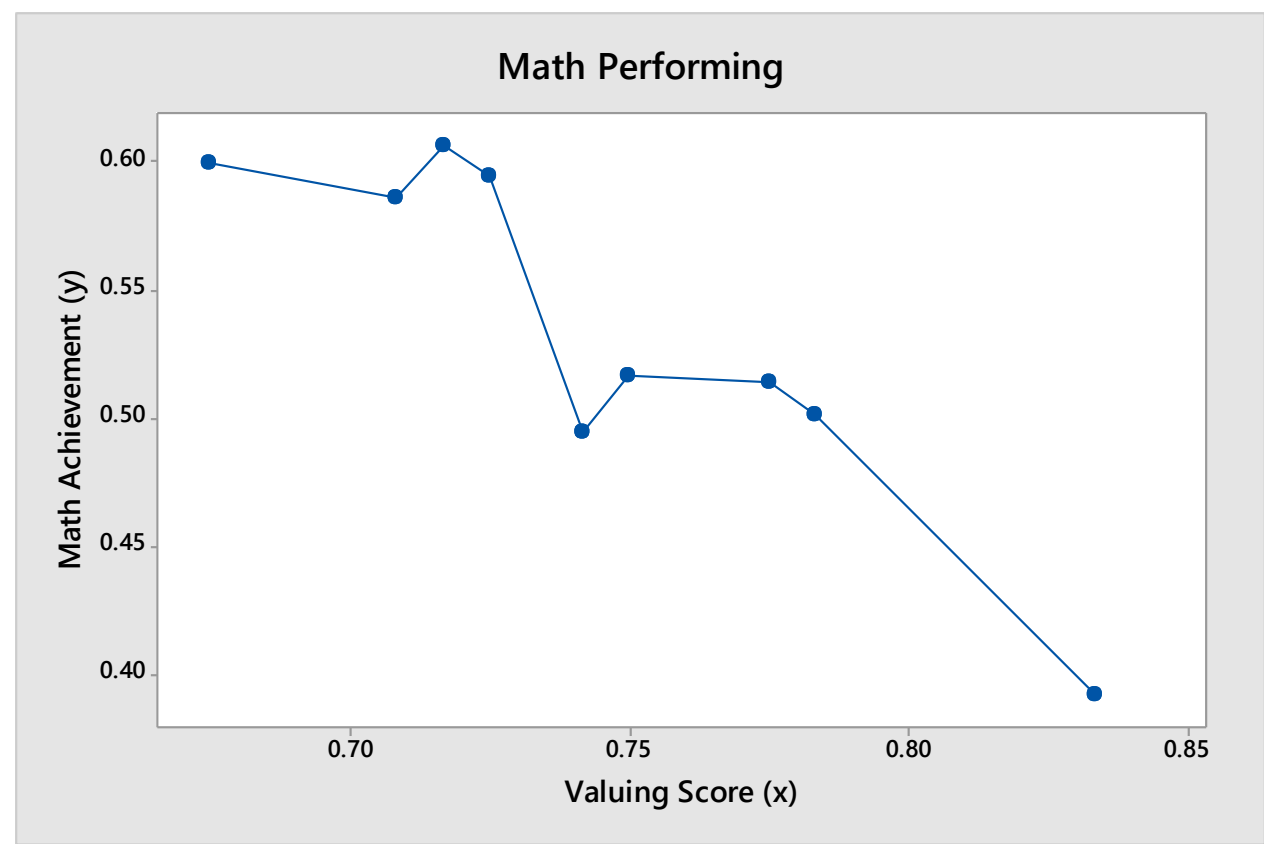

Figure 4. Scatter plot of the Math Performing Countries in terms of Math Achievement and Valuing Score

As shown on figure 6, it is observable in the plot the decline of achievement as valuing to the discipline arise. In the global mathematics classroom, it is composed of few elite students whose skills and knowledge in the area is advanced which are visible in the graph having a performance of average and above. These students see the subject as highly competitive that only few individuals may dwell. Generally, these students discourage learning mathematics not because they do not know the fundamentals and advanced courses but rather it will need great deal for an individual to fully grasped the discipline and excel in the field.

Chinese Taipei, Hong Kong SAR, Korea, Saudi Arabia, Japan, Kuwait, Sweden, Italy, Hungary, and Slovenia have considered math as a leverage to excel internationally. This leverage was used to showcase the competence of their countrymen in the discipline designing their curriculum to be generally competitive.

\section{Equal Weighing Global Classroom}

Learners perform better in the discipline while showing a better valuing in mathematics. Learners showing these emergent characteristics will help the classroom in building an atmosphere geared in the absolute learning of mathematics across other emergent structures. Johnson and Kuennen (2006) exclaimed that performance in class is associated in basic math skills which help the realization of valuing mathematics as a useful tool to be successful in the dynamic and modest society.

IJEME, Vol. 4, No. 1, March 2020, 11-22. 


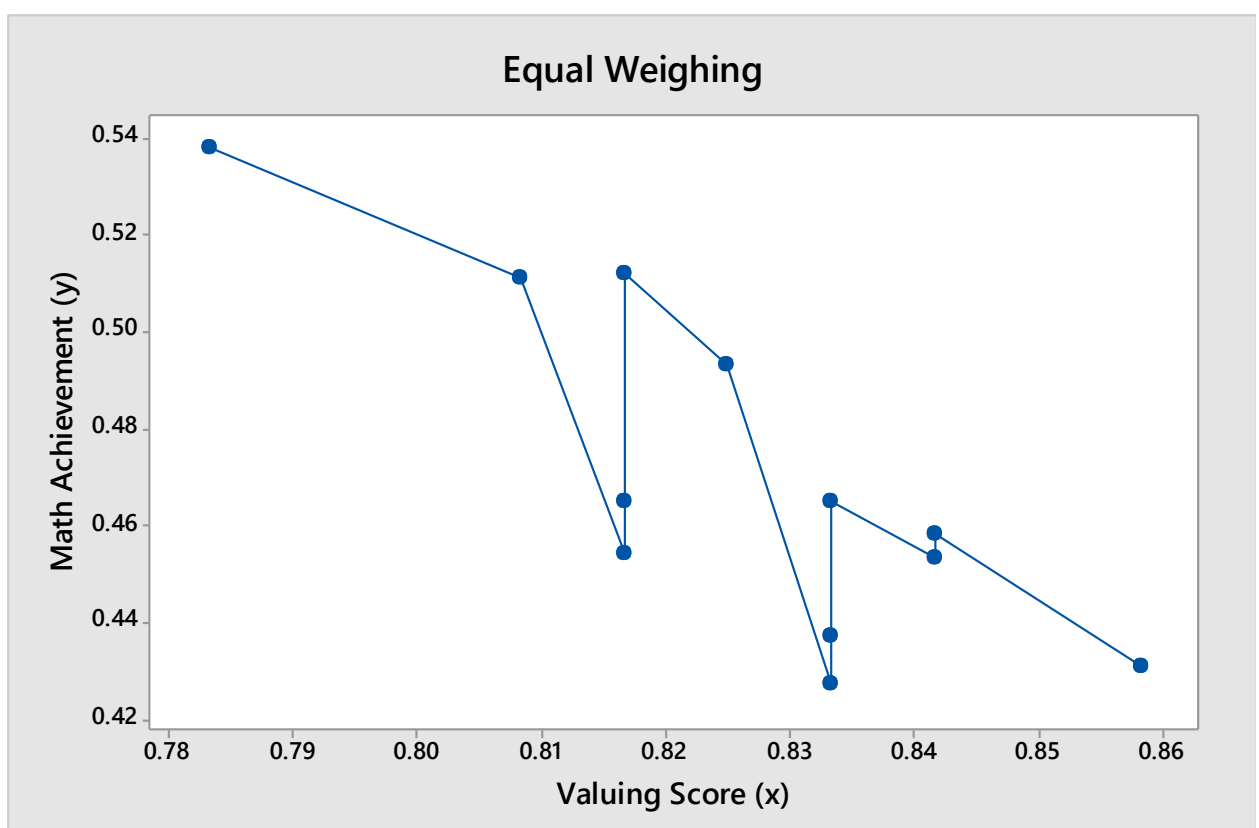

Figure 5. Scatter plot of the Equal Weighing Countries in terms of Math Achievement and Valuing Score

Similar to the other clusters, scatterplot of the equal weighing countries displayed a decreasing pattern of the achievement in mathematics as the valuing of the discipline increases. Difference of these countries namely New Zealand, Lithuania, Norway, Russian Federation, Bahrain, Georgia, Turkey, Malaysia, United Arab Emirates, Chile, Thailand, and Qatar was that they have given equivalent weights in performing in the discipline and at the same time valuing the subject in its application. Regardless of the idea of equal considering, these countries were not successful in making sure that the achievement in mathematics will increase as the valuing to the subject also increases.

\section{Overall Emergent Feature of Global Classrooms}

Direct relationship in terms of the achievement in mathematics and valuing attitude towards the discipline was implicit in common understanding. Results of the study have found out that the two variables have an inverse relationship regardless of which emergent structure the country was categorized. This questions the public knowledge as to how valuing towards the subject was constructed and was found out that the approach in the tool being used was highly utilitarian which focuses on the usage of the discipline as reflected in table 4.

Table 5. The Math Valuing Statements used in TIMSS 2015 International Assessment

\begin{tabular}{ll}
\hline Statements & Nature \\
\hline I think learning mathematics will help me in my daily life. & Utilitarian \\
I need mathematics to learn other school subjects. & Utilitarian \\
I need to do well in mathematics to get into the university of my choice. & Utilitarian \\
I need to do well in mathematics to get the job I want. & Utilitarian \\
I would like a job that involves using mathematics. & Utilitarian \\
It is important to learn about mathematics to get ahead in the world. & Utilitarian \\
\hline
\end{tabular}


Learning mathematics will give me more job opportunities when I am an Utilitarian adult.

My parents think that it is important that I do well in mathematics. Utilitarian

It is important to do well in mathematics.

Utilitarian

The formulation of the statements was highly extrinsic which also reflected in the real-life setting of every mathematics classroom elsewhere in the world. Most teachers have taught mathematics in the approach where they have inculcated in the minds of the students that they need to study mathematics because it will help them in the future. This method has caused dilemma to the student because of the rigorous and complex topics and subtopics of mathematics as the level of the students go higher. The predicament has become an irony of the global classroom because; teachers have given all the possible application of the subject thereby needing the students to take the subjects thus increasing the utility value of the discipline. However, implication of the increasing value has resulted to the decline of achievement of mathematics across countries worldwide.

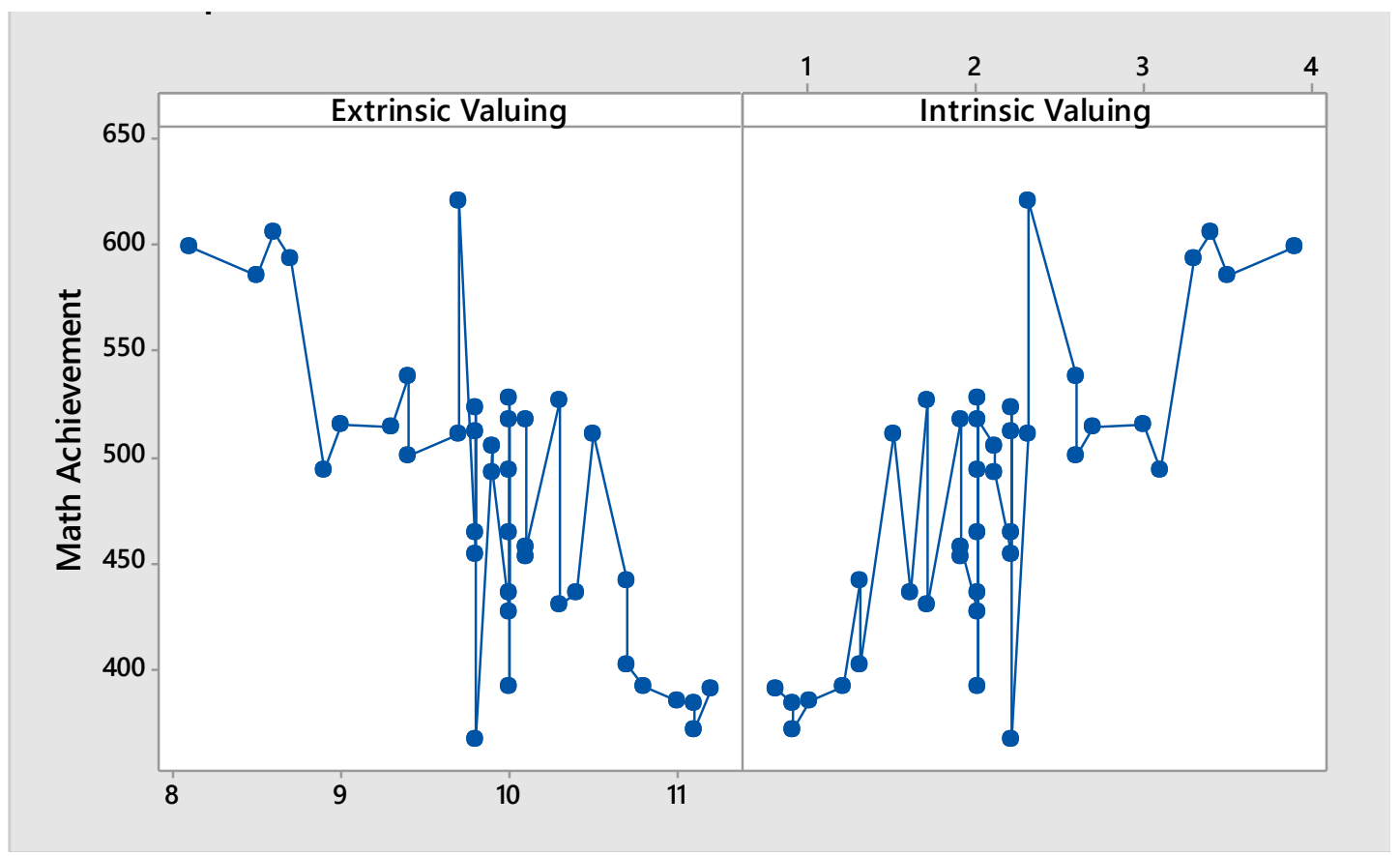

Figure 6. Scatter plot of the Overall Feature of Countries in terms of Math Achievement and Extrinsic and Intrinsic Valuing Score

On the other hand, mathematics classroom have considered the usefulness of the discipline for a long time; teaching the students all the needed mathematics in order to formulate an algorithm which will be useful in the community, but none of which have considered the beauty of mathematics or the aesthetic value of it. A complete shift in the approach of teaching the most hated subject into something as an art that everyone finds to enjoy and express willingly will definitely discourse the pattern in to increasing performance as the aesthetic value of it increases.

\section{CONCLUSION}

Performance in mathematics is a perennial problem that most educators wanted to address. Strategies were designed to capture the culprit of the problem, however, 
still unsuccessful and unclear on how to remove the barriers towards the understanding of mathematics. Affective portion of the students were scrutinized to determine the origin of the deficiency in the achievement through inculcating the importance and usefulness of mathematics yet the approach unpredicted unexpectedly and unknowingly. The study viewed the macro level of the interaction of students where they adapted a pattern in learning mathematics. This pattern generally opts a student whether to perform, to value or to have both at the same time in terms of performance in mathematics. Nonetheless, across the different structure none of which improved the performance when valuing is considered. Tteaching students to value math because of its usefulness do not help in the achievement but when educators shape the learning of mathematics as to how beautiful the discipline, it will surely increase the achievement of mathematics in the long run.

\section{REFERENCES}

Beilock, S. L., \& Willingham, D. T. (2014). Math Anxiety: Can Teachers Help Students Reduce It? Ask the Cognitive Scientist. American educator, 38(2), 28.

Burton, M. (2012). What Is Math? Exploring the Perception of Elementary Pre-Service Teachers. Issues in the Undergraduate Mathematics Preparation of School Teachers, 5.

Fuller, T., \& Moran, P. (2001). Small enterprises as complex adaptive systems: a methodological question? Entrepreneurship \& regional development, 13(1), 47-63.

Trends in International Mathematics and Science Study (2015). TIMSS 2015 and TIMSS Advanced 2015 International Results.

Ma, X., \& Xu, J. (2004). Determining the causal ordering between attitude toward mathematics and achievement in mathematics. American Journal of Education, 110(3), 256-280.

Newell, C. (2008). The class as a learning entity (complex adaptive system): An idea from complexity science and educational research. SFU Educational Review, 2.

Davis, B., \& Sumara, D. (2014). Complexity and education: Inquiries into learning, teaching, and research. Routledge.

Folke, C. (2006). Resilience: The emergence of a perspective for social-ecological systems analyses. Global environmental change, 16(3), 253-267.

Holden, L. M. (2005). Complex adaptive systems: concept analysis. Journal of advanced nursing, 52(6), 651-657.

Lansing, J. S. (2003). Complex adaptive systems. Annual review of anthropology, 32(1), 183-204.

Levin, S. (2003). Complex adaptive systems: exploring the known, the unknown and the unknowable. Bulletin of the American Mathematical Society, 40(1), 3-19.

Ashcraft, M. H., \& Krause, J. A. (2007). Working memory, math performance, and math anxiety. Psychonomic bulletin \& review, 14(2), 243-248.

Karimi, A., \& Venkatesan, S. (2009). Mathematics anxiety, mathematics performance and academic hardiness in high school students. International Journal of Educational Sciences, 1(1), 33-37.

Cavanagh, S. (2008). Low Performers Found Unready to Take Algebra. Education Week, 28(5), 1-12.

Reyna, V. F., \& Brainerd, C. J. (2007). The importance of mathematics in health and human judgment: Numeracy, risk communication, and medical decision making. Learning and Individual Differences, 17(2), 147-159. 
Anderman, E. M., Eccles, J. S., Yoon, K. S., Roeser, R., Wigfield, A., \& Blumenfeld, P. (2001). Learning to value mathematics and reading: Relations to mastery and performance-oriented instructional practices. Contemporary educational psychology, 26(1), 76-95.

Johnson, M., \& Kuennen, E. (2006). Basic math skills and performance in an introductory statistics course. Journal of Statistics Education, 14(2).

Uhrmacher, P. B. (2009). Toward a theory of aesthetic learning experiences. Curriculum Inquiry, 39(5), 613-636.

Greenwood, J. (2011). Aesthetic learning and learning through the aesthetic. In Key concepts in theatre/drama education (pp. 47-52). SensePublishers. 